\title{
Prevention and Management of Bleeding Episodes in Patients with Acquired Hemophilia A
}

\author{
Paul Knöbl ${ }^{1}$ iD \\ Published online: 12 December 2018 \\ (c) The Author(s) 2018
}

\begin{abstract}
Acquired hemophilia A (AHA) is a rare autoimmune disease caused by autoantibodies inhibiting the function of coagulation factor VIII. It is characterized by spontaneous bleeding in patients with no previous family or personal history of bleeding. Although several large registries have collected clinical data on AHA, limited information is available on the optimal management of AHA because controlled clinical trials are lacking. AHA can easily be diagnosed if the problem (prolonged activated partial thromboplastin time in a bleeding patient) is recognized. After the effects of anticoagulants are excluded, low factor VIII activity and the detection of circulating inhibitors confirms the diagnosis. However, lack of familiarity with this rare condition may delay diagnosis and adequate therapy. Treatment of AHA is based on measures for prompt hemostatic control to stop (and prevent) bleeding, immunosuppression to eradicate the autoantibodies, and supportive care for the adverse effects of that treatment and patients' often complex comorbidities. This article gives a comprehensive overview of the current knowledge about the pathophysiology, diagnosis, and treatment of AHA.
\end{abstract}

\section{Key Points}

Acquired hemophilia $\mathrm{A}$ is a rare autoimmune disease that causes severe bleeding.

Hemostatic therapy is complex and expensive, and should be guided by experienced specialists.

The ultimate therapeutic goal is the long-term eradication of the autoantibodies.

\section{Introduction}

Acquired hemophilia A (AHA) is a rare autoimmune disorder characterized by the development of inhibiting autoantibodies to coagulation factor VIII $[1,2]$. The disease is characterized by either spontaneous or induced hemorrhage in patients with no previous family or personal history of bleeding [3, 4]. With the exception of younger women with

Paul Knöbl

paul.knoebl@meduniwien.ac.at

1 Department of Medicine 1, Division of Hematology and Hemostasis, Medical University of Vienna, Währinger Gürtel 18-20, 1090 Vienna, Austria postpartum inhibitors, affected patients are often older and therefore have several other comorbidities that must be considered when caring for such a patient [5]. Although the condition is rare, registry data and large case series on hundreds of patients have been published, all showing a rather consistent pattern of demographical and clinical parameters (Table 1). However, treatment strategies have changed considerably over time, mainly because of the development of a variety of new hemostatic compounds but also because of improved immunosuppressive strategies [6, 7]. Finally, prognostic parameters predicting response to therapy have been developed, allowing individualized therapy [8, 9]. However, to date, no controlled trials have assessed the efficacy of therapeutic strategies. This article gives a comprehensive overview of the current knowledge about the pathophysiology, diagnosis, and treatment of AHA.

\section{Pathophysiology of Acquired Hemophilia A (AHA)}

AHA is caused by an autoimmune process during which autoantibodies directed against functional epitopes of coagulation factor VIII are formed. The immune response is oligoor polyclonal rather than monoclonal, and the autoantibodies can be of various classes and subclasses of immunoglobulins 
Table 1 Publications on large acquired hemophilia A collectives [5, 7]

\begin{tabular}{|c|c|c|c|c|c|c|c|}
\hline & $\begin{array}{l}\text { Green and } \\
\text { Lechner [15] }\end{array}$ & $\begin{array}{l}\text { Delgado et al. } \\
\text { [16] }\end{array}$ & $\begin{array}{l}\text { Collins et al. } \\
{[14]}\end{array}$ & $\begin{array}{l}\text { Knoebl et al. } \\
\text { (EACH2) [5] }\end{array}$ & $\begin{array}{l}\text { Borg et al. } \\
\text { (SACHA) [29] }\end{array}$ & $\begin{array}{l}\text { Kessler et al. } \\
\text { (HTRS) [20] }\end{array}$ & $\begin{array}{l}\text { Tiede et al. } \\
(\text { GTH) [9] }\end{array}$ \\
\hline $\begin{array}{l}\text { Collection } \\
\text { period }\end{array}$ & Before 1981 & $1985-2002$ & 2001-2003 & 2003-2009 & 2001-2006 & $2000-2011$ & 2010-2013 \\
\hline Study design & $\begin{array}{l}\text { Retrospective } \\
\text { survey }\end{array}$ & Meta-analysis & $\begin{array}{l}\text { Prospective } \\
\text { surveillance, } \\
\text { predefined } \\
\text { population }\end{array}$ & $\begin{array}{l}\text { Multicentre } \\
\text { registry }\end{array}$ & $\begin{array}{l}\text { Prospective } \\
\text { follow-up }\end{array}$ & Retrospective & $\begin{array}{l}\text { Prospective, } \\
\text { predefined } \\
\text { immunosup- } \\
\text { pression }\end{array}$ \\
\hline Region & World & World & UK & Europe & France & USA & Germany, Austria \\
\hline Patients $(N)$ & 215 & 234 & 172 & 501 & 82 & 166 & 124 \\
\hline Age, years & $\begin{array}{l}57 \\
(<10-90)\end{array}$ & $\begin{array}{l}64 \\
(8-93)\end{array}$ & $\begin{array}{l}78 \\
(2-98)\end{array}$ & $\begin{array}{l}74 \\
(13-102)\end{array}$ & $\begin{array}{l}77 \\
(25-103)\end{array}$ & $\begin{array}{l}70 \\
(13-92)\end{array}$ & $\begin{array}{l}74 \\
(26-97)\end{array}$ \\
\hline$\%$ Male & 53 & 45 & 45 & 53 & 61 & 48 & 58 \\
\hline $\begin{array}{l}\text { Factor VIII } \\
\text { activity (\%) }\end{array}$ & NR & $\begin{array}{l}2 \\
(0-30)\end{array}$ & $\begin{array}{l}3 \\
(<1-25)\end{array}$ & $\begin{array}{l}2 \\
(<1-40)\end{array}$ & $\begin{array}{l}2 \\
(0-30)\end{array}$ & NR & $\begin{array}{l}1.4 \\
(<1-31)\end{array}$ \\
\hline $\begin{array}{l}\text { Inhibitor titer } \\
(\mathrm{BU} / \mathrm{mL})\end{array}$ & NR & $\begin{array}{l}10 \\
(0.9-32,000)\end{array}$ & $\begin{array}{l}7 \\
(40.8-717)\end{array}$ & $\begin{array}{l}12.8 \\
(0.1-28,000)\end{array}$ & $\begin{array}{l}16 \\
(1-2800)\end{array}$ & $\begin{array}{l}50 \\
(1-2969)\end{array}$ & $\begin{array}{l}19 \\
(1-1449)\end{array}$ \\
\hline \multicolumn{8}{|c|}{ Underlying disorders (\%) } \\
\hline $\begin{array}{c}\text { None (idi- } \\
\text { opathic) }\end{array}$ & 46.1 & 57.7 & 63.3 & 51.9 & 55 & 44.1 & 44.1 \\
\hline $\begin{array}{r}\text { Malignancy } \\
\text { (any type) }\end{array}$ & 6.7 & 18.4 & 14.7 & 11.8 & 19.5 & 14.5 & 14.5 \\
\hline $\begin{array}{l}\text { Autoimmune } \\
\text { disorder }\end{array}$ & 18.0 & 9.4 & 16.7 & 11.6 & 15 & 18.6 & 28.3 \\
\hline Postpartum & 7.3 & 14.5 & 2.0 & 8.4 & 7.3 & 3.4 & 3.4 \\
\hline Infections & NR & NR & NR & 3.8 & NR & NR & NR \\
\hline $\begin{array}{l}\text { Dermatologi- } \\
\text { cal condi- } \\
\text { tions }\end{array}$ & 4.5 & NR & 3.3 & 1.4 & NR & NR & NR \\
\hline Drug induced & 5.6 & NR & NR & 3.4 & NR & NR & NR \\
\hline Other & 11.8 & NR & NR & 11.6 & NR & 38.6 & 4.8 \\
\hline
\end{tabular}

Data are presented as $n(\%)$ or median (range) unless otherwise indicated

$N R$ not reported

and may have very different binding characteristics $[8,10$, 11]. Whereas almost all patients $(95 \%)$ have immunoglobulin G4 (IgG4) autoantibodies to factor VIII, up to $46 \%$ have also autoantibodies to other subclasses (Table 2). Moreover, the characteristics of the autoantibodies can change and evolve during the autoimmune response and during immunosuppressive therapy [10]. The subclass pattern of the autoantibodies has a prognostic value: Patients with $\operatorname{Ig} \mathrm{A}$ anti-factor VIII antibodies have a lower probability of remission and higher mortality rates $[8,11]$. The autoantibodies

Table 2 Autoantibody subclass pattern in patients with acquired hemophilia A [8]

\begin{tabular}{llcc}
\hline Isotype or subclass & Positive screening & Titer in positive patients & Apparent affinity, $n ; K_{\mathrm{A}}\left[\mathrm{M}^{-1}\right]$ \\
\hline IgG1 & $71(88)$ & $1: 640(1: 320-1: 2560)$ & $70 ; 1.4 \times 10^{10}\left(0.8 \times 10^{10}-4.2 \times 10^{10}\right)$ \\
IgG2 & $62(77)$ & $1: 80(1: 40-1: 320)$ & $40 ; 1.9 \times 10^{9}\left(1.0 \times 10^{9}-3.2 \times 10^{9}\right)$ \\
IgG3 & $33(41)$ & $1: 80(1: 40-1: 320)$ & $19 ; 1.3 \times 10^{10}\left(0.5 \times 10^{10}-1.8 \times 10^{10}\right)$ \\
IgG4 & $79(98)$ & $1: 5120(1: 1280-1: 20,480)$ & $77 ; 5.8 \times 10^{10}\left(2.4 \times 10^{10}-1.3 \times 10^{11}\right)$ \\
IgA & $37(46)$ & $1: 80(1: 40-1: 160)$ & $18 ; 1.7 \times 10^{9}\left(0.9 \times 10^{9}-4.6 \times 10^{9}\right)$ \\
IgM & $7(9)$ & $1: 80(1: 40-1: 80)$ & $\mathrm{ND}$ \\
\hline
\end{tabular}

Data are presented as $n(\%)$ or median (interquartile range) unless otherwise indicated

Ig immunoglobulin, $N D$ not determined 
partially or completely neutralize the activation or function, or accelerate the clearance, of factor VIII.

This immune response is very different from congenital hemophilia A, wherein affected patients may also develop inhibitory antibodies against FVIII following exposure to exogenous FVIII during substitution therapy, but these alloantibodies have different laboratory and clinical properties. In congenital hemophilia A, alloantibodies typically inactivate FVIII completely with a linear (type 1) kinetics, dependent on both concentration and time. In contrast, in AHA, autoantibodies show a type 2 kinetics with a rapid initial inactivation phase followed by a slower equilibrium phase, dependent on temperature and time, and some residual FVIII activity can be detected in vitro, even with hightiter inhibitors. The Bethesda assay may therefore underestimate the in vivo inhibitor potency in AHA because of the complex nonlinear autoantibody kinetics $[12,13]$. Consequently, FVIII activity or inhibitor titer cannot be used to predict the severity of bleeding events and identify patients with AHA who are at high risk of fatal bleeding episodes, but factor VIII levels are useful to predict the course of the disease, i.e., rate of remission, time to remission, and overall survival $[9,11]$.

\section{Demographics of AHA}

AHA is a rare condition with an estimated incidence of approximately 1.5 per million population per year [14]. A series of reports (registry data and large case series) have been published since 1980 (Table 1) and provide deep insight into the demographic and clinical characteristics of patients with AHA. In 1981, Green and Lechner [15] published a retrospective survey on 215 patients with AHA referred to specialist centers. In 2003, Delgado et al. [16] performed a meta-analysis of all reports on AHA published between 1985 and 2002, comprising 249 patients from 21 case series. Later, the UK Haemophilia Centre Doctors Organisation (UKHCDO) performed a prospective surveillance study, collecting data on all 172 patients with AHA who presented in the UK between 2001 and 2003 [14]. This created a consecutive cohort of patients unaffected by referral and reporting bias, which enabled reliable calculations of incidence, characteristics, and outcomes of patients with AHA. In 2010, results from the EACH2 registry, which collected data on 501 patients with AHA from 13 European countries between 2003 and 2008, making it the largest prospective collection of patients with AHA to date, have provided deeper insight into the demographics and underlying disorders associated with AHA [5, 17-19]. The HTRS registry, conducted in the USA, comprised a more ethnically diverse population, as $24 \%$ of patients were Black [20]. This incidence appears overrepresented compared with the percentage of Black people within the US population (13.6\%) and suggests that Black individuals could be preferentially affected by AHA, as they are for allo-FVIII antibodies [20]. The GTH-AH 10/2010 study comprised 102 patients treated with a standardized escalating immunosuppressive protocol to identify factors predicting the course of the disease [9].

All these publications demonstrate a rather consistent demographical pattern: The median age of patients with AHA is about 70 years, with a small population of women of childbearing age who develop factor VIII inhibitors in association with pregnancy (postpartum inhibitors). Male patients have a slightly higher incidence than females. In half of the patients, no underlying or predisposing disease could be identified ("idiopathic AHA"). Malignancy, pregnancy, infections, certain medications, and other autoimmune diseases have been associated with AHA. At presentation, the factor VIII activity levels of patients may be severely suppressed $(<1 \%$ of normal) but can also be in a higher and apparently safe range. Nevertheless, the characteristics of the antibodies mean that even those patients may develop severe bleeding. The typical median titer of the inhibitors is $20 \mathrm{BU} /$ $\mathrm{mL}$, with a broad range between barely detectable inhibitors and very high titers. However, the titers in these publications have been measured with quite different methods and are therefore not completely comparable.

\section{Clinical Features of AHA}

AHA can cause severe bleeding complications, with lifethreatening bleeding episodes reported in $97 \%$ of patients $[5,17]$. Patients with AHA can seemingly experience more severe bleeding episodes than those with congenital hemophilia with comparable FVIII levels.

The bleeding pattern seen in AHA is different from that observed in congenital hemophilia A (Table 3). Typically, bleeding episodes occur spontaneously and present with skin or soft-tissue bleeding in individuals with no personal or family history of bleeding. Extensive skin hematomas, severe muscle bleeding, retroperitoneal bleeding, epistaxis, hematuria, gastrointestinal bleeding, and even intracerebral bleeds are more frequent than joint bleeding. In comparison, hemarthroses account for approximately $70-80 \%$ of bleeding episodes in patients with congenital hemophilia A. Recent data from the $\mathrm{EACH} 2$ registry have provided detailed information on the bleeding phenotype of AHA [5] (Table 3). In the majority of patients $(90 \%)$, a bleeding event triggered clotting testing and led to the diagnosis of AHA. Most of these bleedings (77.4\%) were spontaneous, and less than $10 \%$ were associated with trauma, surgery, or pregnancy complications. Two-thirds of the patients had 
Table 3 Bleeding phenotype of patients with acquired hemophilia A

\begin{tabular}{lc}
\hline Phenotype & Median (IQR) or (\%) \\
\hline Severity & 70.3 \\
Severe & 28.9 \\
Non-severe & 0.8 \\
Not reported & \\
Location ${ }^{\mathrm{a}}$ & 53.2 \\
Skin & 50.2 \\
Deep muscle, retroperitoneal & 31.3 \\
Mucosa & 4.9 \\
Joints & 1.1 \\
Brain & 6.6 \\
No bleeding & \\
Cause & \\
Spontaneous & 77.4 \\
Traumatic & 8.4 \\
Surgery & 8.2 \\
Peripartal & 3.6 \\
Other & 2.7 \\
Time from bleeding to AHA diagnosis & \\
Median (days) & $3(0-12)$ \\
Up to 1 day & 37.2 \\
Up to 1 week & 26.1 \\
Up to 1 month & 22.4 \\
More than 1 month & 11.1 \\
\hline
\end{tabular}

Data are from the $\mathrm{EACH} 2$ registry, the largest collection of patients with AHA [5]

$A H A$ acquired hemophilia A, IQR interquartile range

${ }^{a}$ Some patients had more than one bleeding site

${ }^{b}$ Some patients had more than one reason for bleeding

only one bleeding event, but one-third had one or more (up to six) relapses $[5,17]$.

Although the bleeding phenotype remains unchanged, the risk of dying from bleeding has reduced considerably with the development of effective hemostatic therapy. Green and Lechner [15] reported mortality from bleeding of $20 \%$ before 1981 [15], whereas only $2.9 \%$ of patients in the GTH trial from 2010 bled to death [7, 9].

\section{Diagnosis of AHA}

AHA should be suspected when new, unexpected bleeding occurs in a patient with no previous personal and family history of bleeding, especially in elderly or postpartum patients. Global coagulation tests usually show an isolated prolongation of the activated partial thromboplastin time (APTT) (normal prothrombin time, fibrinogen level, platelet counts). Such a constellation should prompt advanced clotting tests to confirm the diagnosis. However, lack of familiarity with the disease can result in a considerably delayed diagnosis, which may affect treatment selection, initiation, and outcomes. The EACH2 registry showed that $37 \%$ of patients were definitely diagnosed with AHA within 1 day and $26 \%$ within 1 week of initial bleeding [5]. However, a considerable diagnostic delay was obvious in one-third of the patients (up to 1 month in $22 \%$, more than 1 month in $11.1 \%$ of cases) [5]. Although diagnostic delay significantly prolonged the time to start of hemostatic therapy, no difference in response to therapy, intensity of therapy, or outcome was demonstrated. However, patients still remain at unnecessary risk of severe bleeding episodes until the inhibitor has been eradicated.

Extended coagulation testing should follow an algorithm [7] to rule out other causes of APTT prolongation or bleeding (Fig. 1). As most patients are older at diagnosis and probably being treated with anticoagulants for atrial fibrillation or arterial or venous thromboembolism, the effects of anticoagulants should be appropriately ruled out as a first step: a prolonged thrombin clotting time is always a sign for effects of heparin or direct thrombin inhibitor drugs, and a positive anti-Xa test is a sign for low-molecular-weight heparins, heparinoids, fondaparinux, or direct factor $\mathrm{Xa}$ inhibitor drugs. The effects of vitamin $\mathrm{K}$ antagonists would also lead to an abnormal prothrombin time. After ruling out anticoagulant effects, the next step would immediately be extended coagulation testing when available (single clotting factor activities of factors XII, XI, IX, and VIII; APTT with different reagents; plasma mixing studies to demonstrate circulating inhibitors). If no extended clotting testing is available, plasma mixing studies testing for APTT immediately after mixing and after $2 \mathrm{~h}$ of incubation at $37{ }^{\circ} \mathrm{C}$ are helpful to demonstrate that inhibitors are present in the patient's plasma, which should lead to extended clotting testing anyway.

AHA is diagnosed by reduced activity of factor VIII (below 50\%). Acquired von Willebrand syndrome is also associated with bleeding and low factor VIII levels so must be ruled out. Very low $(<1 \%)$ levels of factor VIII are associated with a lower rate of and a longer time to remission and with poorer overall survival $[8,9,11]$. Risk of bleeding is not associated with factor VIII level; even patients with somewhat higher levels may develop severe bleeding.

Quantification of the inhibitor titer is complicated in AHA because of the above-mentioned kinetics and the residual factor VIII activity. The classical Bethesda assay has many limitations $[12,13]$ that are partly solved by the Nijmegen modification [21] or other measures (heat treatment) $[13,22]$. This leads to considerable inter-laboratory variations in inhibitor results [13]. Immunological methods (enzyme-linked immunosorbent assay [ELISA] assay testing for factor VIII binding antibodies) are limited in that even 


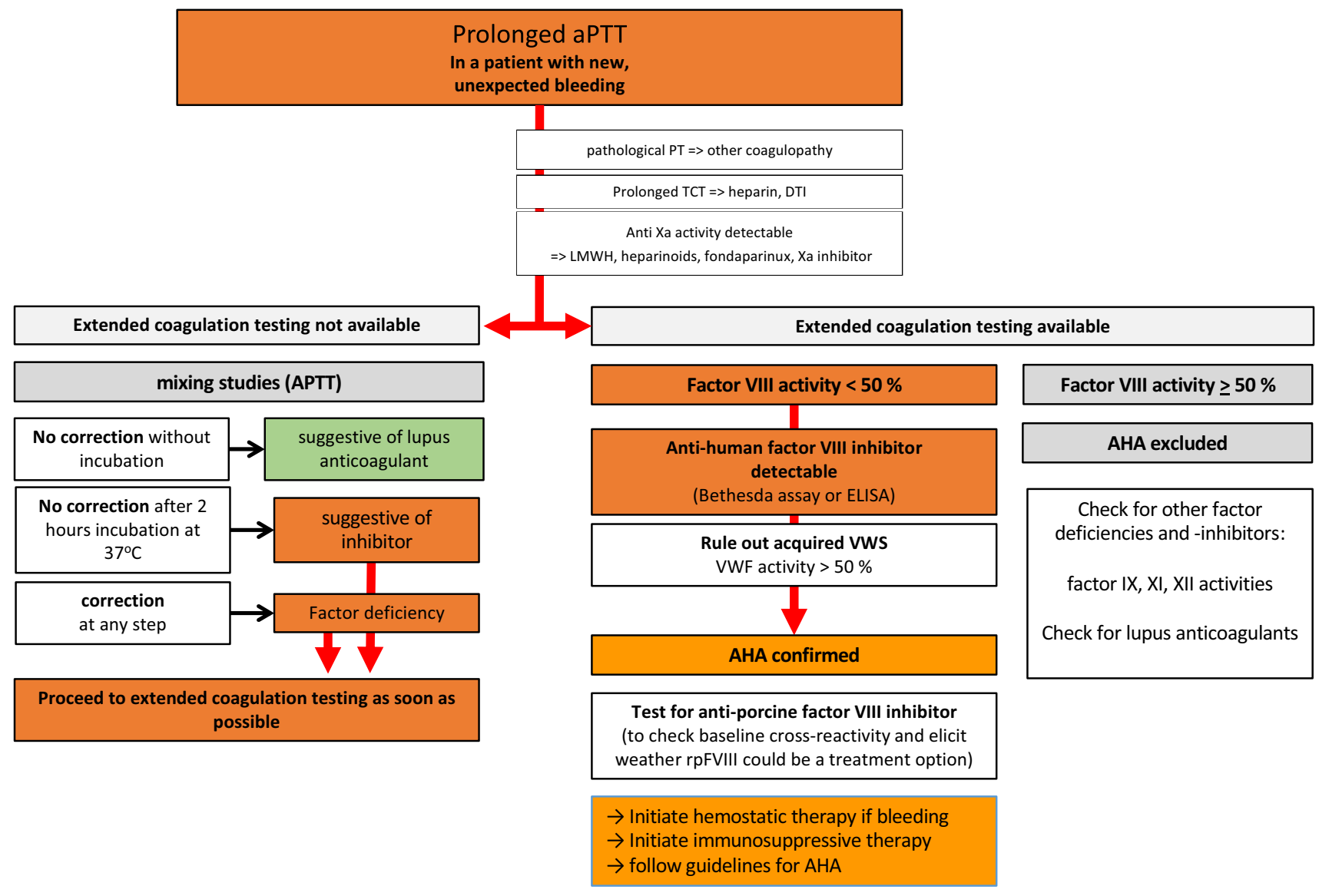

Fig. 1 Diagnostic algorithm for acquired hemophilia A. Modified from Kruse-Jarres et al. [7]. AHA acquired hemophilia A, APTT activated partial thromboplastin time, DTI direct thrombin inhibitor,

non-inhibiting antibodies are detected. Depending on the applied method and the quality of the laboratory, the inhibitor titer may be a predictor for the rate and time to remission and may therefore be used to individualize the therapy of patients with AHA $[9,11]$.

\section{Clinical Management}

Clinical management of patients with AHA is based on four principles:

- hemostatic therapy of the acute bleeding event and prevention of further bleeding

- fast reduction of the inhibitor titer (if possible) to enable better hemostatic therapy

- termination of the underlying autoimmune process

- individualized supportive therapy.

These principles have been followed for many years, but recent developments in the understanding of the
ELISA anti human FVIII antibody enzyme-linked immunosorbent assay, $L M W H$ low molecular weight heparin, $P T$ prothrombin time, $T C T$ thrombin clotting time, $V W F$ von Willebrand factor

pathophysiology, prognostic factors, hemostatic and immunosuppressive therapy, and extracorporeal methods have changed the philosophy of AHA management from acute, aggressive, and dangerous therapy to individualized, riskadapted, mild methods to care for these vulnerable patients $[7,23,24]$.

\subsection{Treatment of Acute Bleeding Episodes}

Hemostatic therapy in AHA is indicated in patients with acute major bleeding (defined as unstable hemoglobin/ hematocrit levels, need for transfusions, deep muscle, retroperitoneal, gastrointestinal or cerebral bleeding). In such situations, hemostatic therapy needs to be easily available and applicable, reliable and highly efficacious, and with a low rate of side effects. In patients with high factor VIII inhibitor titers ( $>5 \mathrm{BU} / \mathrm{mL})$, replacement with human factor VIII concentrates, even at very high doses, is ineffective, as the antibodies will immediately block all the factor VIII administered. Porcine factor VIII may be an option, 
but cross-reactivity is possible, and the initial efficacy is not predictable. Therefore, to date, bypassing agents and recombinant porcine factor VIII are approved for this indication, are recommended by current guidelines, [6, 7, 17, 24]. Table 4 summarizes the currently approved possibilities for hemostatic treatment of patients with AHA.

Patients with mild or no bleeding may also need hemostatic therapy to prevent bleeding, as they are at high risk for (spontaneous or induced) severe bleeding. Such patients need a different approach: dosing of bypassing agents can be lower, porcine (and even human) factor VIII can be tried, and in vivo recovery and trough levels can be measured. In future, even emicizumab can be a good option for such patients (see Sect. 6.1.3.1).

Nevertheless, any injury to or breach of the body's integrity will immediately lead to severe bleeding. Therefore, any invasive interventions need to be strictly avoided. Even large hematomas or deep muscle bleeding will resolve within a few days when sufficient hemostatic therapy is applied; hematoma evacuation or fasciotomy is not indicated.

\subsubsection{Bypassing Agents}

Bypassing agents improve hemostasis in patients with hemophilia and inhibitors, as well as in AHA, by bypassing the need for factor VIII to generate sufficient thrombin. Recombinant human activated factor VII (rhFVIIa) and activated prothrombin complex concentrates (APCC) are available and used in the majority of patients with AHA [12, 23, 25]. Both substances are equally effective in this indication, with a
93\% rate of success [17]. Thus, bypassing agents are remain the treatment of choice for AHA [7, 23, 26].

However, they do have some clinical shortcomings: it is not possible to monitor these drugs with conventional laboratory assays, even not with the modern thrombin-generation assays. Therefore, only clinical response of the bleeding is helpful to guide treatment (increase or reduce dose and/or intervals), which is rather unsatisfactory for such expensive medications. Moreover, there is a higher risk for thromboembolism, especially in elderly and comorbid patients.

\subsubsection{Recombinant Human Activated Factor VII} (Novoseven ${ }^{\oplus}$ ) rhFVIIa has been approved for many years for the treatment of patients with congenital and acquired hemophilia with inhibitors, for factor VII deficiency, and for Glanzmann's thrombasthenia [27, 28]. Excess of activated factor VII leads to a burst of thrombin generation without the need for factor VIII. As the half-life of rhFVIIa is short, it is typically dosed at $90 \mu \mathrm{g} / \mathrm{kg}$ body weight every $2 \mathrm{~h}$. Dose and/or intervals may be modified according to clinical response. Trial and registry data show that rhFVIIa is used in the majority of patients with AHA with a high rate of success and a low rate of associated thromboembolic complications [5, 14, 17, 20, 29-32]. Data from EACH2 show that patients were treated with a median of 12 doses in 3-h intervals for their initial bleeding. rhFVIIa is available in most hospitals, as it is frequently used (off-label) in trauma centers or emergency departments as a potent hemostatic medication.

Table 4 Hemostatic therapy for acquired hemophilia A

\begin{tabular}{ll} 
Bypassing agents & \\
\hline $\begin{array}{l}\text { Recombinant human acti- } \\
\text { vated factor VII }\end{array}$ & $\begin{array}{l}\text { Activated prothrombin } \\
\text { complex concentrate }\end{array}$
\end{tabular}

\begin{tabular}{lll}
\hline Brand name & Novoseven $^{\circledR}$ & FEIBA $^{\circledR}$ \\
Indication in AHA & $\begin{array}{l}\text { Independent of inhibitor } \\
\text { titer }\end{array}$ & $\begin{array}{c}\text { Independent of inhibitor } \\
\text { titer }\end{array}$
\end{tabular}

Initial dose

$90 \mu \mathrm{g} / \mathrm{kg}$ every $2 \mathrm{~h}$

Laboratory monitoring Not possible

Therapeutic target

Clinical response

Advantages

High efficacy

No maximum dose

Disadvantages
$70 \mathrm{U} / \mathrm{kg}$ every $8 \mathrm{~h}$ max. $200 \mathrm{U} / \mathrm{kg} /$ day

Not possible

Clinical response

High efficacy

\section{Maximum dose}

Risk of coagulopathy

High treatment costs
Short dosing intervals High treatment costs
Factor VIII concentrates

Human factor VIII concen- Recombinant porcine factor trate (plasma-derived or VIII concentrate recombinant)

\begin{tabular}{|c|c|}
\hline Various & Obizur $^{\circledR}$ \\
\hline $\begin{array}{l}\text { Low inhibitor titer }(<5 \mathrm{BU} / \\
\mathrm{mL}) \text { and good post- } \\
\text { infusion recovery }\end{array}$ & Dependent on cross reactivity \\
\hline $70 \mathrm{U} / \mathrm{kg}$ every $8 \mathrm{~h}$ & $\begin{array}{l}\text { 50-200 U/kg; interval } \\
\text { dependent on recovery }\end{array}$ \\
\hline Factor VIII activity & Factor VIII activity \\
\hline $\begin{array}{l}\text { Clinical response; factor } \\
\text { VIII trough level }>50 \%\end{array}$ & $\begin{array}{l}\text { Clinical response; factor VIII } \\
\text { trough level }>50 \%\end{array}$ \\
\hline $\begin{array}{l}\text { Laboratory monitoring } \\
\text { possible } \\
\text { Antibody saturation lower } \\
\text { treatment costs }\end{array}$ & $\begin{array}{l}\text { Laboratory monitoring } \\
\text { possible }\end{array}$ \\
\hline Low efficacy & $\begin{array}{l}\text { Possible cross reactivity; } \\
\text { induction of anti-porcine } \\
\text { antibodies } \\
\text { High treatment costs }\end{array}$ \\
\hline
\end{tabular}

$A H A$ acquired hemophilia A 
6.1.1.2 Activated Prothrombin Complex Concentrates (APCC; FEIBA ${ }^{\oplus}$ ) APCC has been approved for many years for the treatment of patients with congenital and acquired hemophilia with inhibitors [33-35]. As APCC comprises activated clotting factors, mostly activated factor VII, its mechanism of action is similar to that of rhFVIIa [36, 37]. APCC is usually administered at a dose of $70 \mathrm{U} / \mathrm{kg}$ every $8 \mathrm{~h}$ (with a warning not to exceed $100 \mathrm{U} / \mathrm{kg}$ single dose and $200 \mathrm{U} / \mathrm{kg}$ daily dose). Doses and/or intervals may be modified according to clinical response. Trial and registry data show that APCC is used frequently in patients with AHA with a high rate of success and a low rate of associated thromboembolic complications [9, 14, 17, 20, 29]. However, there is a low risk of consumption coagulopathy, especially in patients with other risk factors (active cancer, infection, higher age, trauma, surgery, etc.), and APCC should be used with special attention in such patients (monitoring of platelet counts and fibrinogen, D-dimer, and antithrombin levels) [33].

\subsubsection{Factor VIII Replacement Therapy}

Replacement with factor VIII to increase factor VIII activity levels is possible when the anti-factor VIII inhibitor titer is low, but even low titers considerably reduce post-infusion in vivo recovery peak and trough levels. Therefore, very high doses of factor VIII concentrates are necessary to overcome the inhibitors. This applies for both human and porcine factor VIII concentrates. In contrast, if sufficient post-infusion levels can be obtained, replacement therapy can easily be guided with conventional factor VIII activity assays, and treatment is cheaper than with bypassing agents. In addition, there is some evidence that high doses of factor VIII replacement may saturate the circulating inhibitors and lead to a faster elimination, similar to the immunotolerance-induction protocols for congenital hemophilia [38]. However, classical immunotolerance is not an option for AHA, as endogenous factor VIII is always present.

\subsubsection{Human Factor VIII Concentrates (Plasma-Derived} or Recombinant) Human factor VIII concentrates, either plasma derived or recombinant, have been available for many years for the treatment of hemophilia A. As mentioned, the circulating inhibitors in AHA mean human factor VIII concentrates need to be administered at high doses (starting with $70 \mathrm{U} / \mathrm{kg}$ every $8 \mathrm{~h}$ ), guided by the factor VIII levels obtained [12, 23, 24]. During treatment with human factor VIII concentrates, regular measurements of factor FVIII plasma levels (trough levels and post-infusion levels and in vivo recovery) are necessary to guide dosing. Particularly in patients with active bleeding, factor VIII trough levels of $>50 \%$ are necessary. Hemostatic efficacy of human factor VIII concentrates is much lower than with bypassing agents, as demonstrated in various studies (i.e., the $\mathrm{EACH} 2$ data) [17].

Attempts to lower the inhibitor titers with extracorporeal immunoadsorption have been shown to be effective (in terms of a faster switch from bypassing agents to factor VIII replacement and considerably reduced treatment costs), but recent developments (availability of adsorption columns and devices; knowledge of antibody subclasses; changes in immunosuppression by use of rituximab; upcoming availability of non-factor therapy; etc.) means the use of immunoadsorption in AHA has almost ceased in most centers [39-43].

\subsubsection{Recombinant Porcine Factor VIII Concentrate} (Obizur $\left.{ }^{\circledast}\right)$ Factor VIII concentrates from other species have a slightly different amino acid sequence than that from humans, such as a different antigenic structure. This means the autoantibodies would not (or to a lower extent) bind and inhibit and that this factor VIII could be used as replacement therapy when no cross reactivity of the autoantibodies with porcine factor VIII is detectable. A recombinant porcine sequence factor VIII (rpFVIII) concentrate $\left(\right.$ Obizur $^{\circledR}$ ) was recently approved in the USA, Canada, and Europe for the treatment of bleeding in AHA [44-46] based on a prospective, open-label, phase II/III study in 28 adults with serious bleeding [47]. In that study, treatment was initiated with a single $200 \mathrm{U} / \mathrm{kg}$ dose of rpFVIII, and subsequent dosing was adjusted according to clinical response and factor VIII activity. Patients without cross reactivity of the antibodies achieved very high post-infusion factor VIII levels (between 118 and 522\%), suggesting that a much lower initial dose may also be sufficient $[48,49]$. After $24 \mathrm{~h}$ of repetitive infusions, all 28 patients had a good response, suggesting saturation of the remaining antibodies. Bleeding was controlled in $85.7 \%$ of patients. To predict the effectiveness of rpFVIII in the treatment of AHA, it is essential to determine the baseline anti-porcine factor VIII inhibitor titer (cross reactivity), but this is possible only with special reagents. Administration of rpFVIII may also lead to an increase in or new development of anti-rpFVIII antibodies, which may also target the (human) factor VIII of the patient [47]. During treatment with rpFVIII, factor FVIII plasma levels must be measured regularly (trough levels and post-infusion levels and in vivo recovery) to guide dosing and detect antibody development.

\subsubsection{Non-Factor Therapies}

6.1.3.1 Emicizumab (Hemlibra ${ }^{\circledR}$ ) Emicizumab is a bispecific, factor VIIIa mimetic antibody. It targets both factor IXa and X, leading to faster activation of factor X, thus acting like factor VIIIa [50]. It is already approved and available for the prevention of bleeding in patients with hemophilia A with inhibitors. However, clinical trials have been 
conducted only in patients with congenital hemophilia, where emicizumab impressively reduced the annualized bleeding rate to almost zero [51-53]. These patients, who previously required prophylactic intravenous injections of bypassing agents, can now be better treated with a subcutaneous injection of emicizumab every 1 or 2 weeks. It is also effective in congenital hemophilia without inhibitors, with as little as one subcutaneous injection every 4 weeks [54]. Some patients with AHA have been treated with emicizumab outside clinical studies with interesting responses [55]. The principle of action would allow the use of emicizumab in this indication. The advantages would be the possibility of effective hemostatic prophylaxis with weekly or bi-weekly subcutaneous therapy, possibly in an outpatient setting because of the long half-life. The total treatment costs would also be considerably lower than with bypassing agents. Disadvantages include that therapeutic levels are reached after 3 weeks when administered subcutaneously, and acute bleedings cannot be treated this way. Although an intravenous push infusion is possible, which leads to therapeutic levels within minutes, that form of administration is not approved, and adverse effects cannot yet be estimated. Treatment monitoring is complicated: chromogenic factor VIII assays need to be used, inhibitor assays cannot be performed with conventional reagents [56], and the timepoint of remission cannot be determined exactly; combination with APCC is strictly contraindicated because of the high risk of (lethal) thrombotic microangiopathy [53]. Combination with rhFVIIa is possible but with an increased risk of thromboembolism. Combination with factor VIII concentrates (human or porcine), and even endogenous factor VIII in AHA, will compete with emicizumab from its binding sites (and maybe prolong its half-life) but not lead to thromboembolism.

\subsubsection{Anti-Tissue-Factor Pathway Inhibitor Ther-} apy Blocking the tissue-factor-pathway inhibitor (TFPI) is a way to enhance hemostasis by inhibiting regulatory pathways. TFPI downregulates the extrinsic pathway of blood coagulation, thus modulating thrombin generation. Several antibodies and aptamers, targeting various domains of TFPI are under development. Concizumab, PF-06741086, BAY 1093884, and ARC19499 are currently under clinical development for patients with congenital hemophilia with and without inhibitors [57], but no study is active for AHA. Nevertheless, these drugs have the potential to be effective in AHA, but the possible prothrombotic risk in the elderly or comorbid patient must be considered.

6.1.3.3 Other Non-Factor Therapy Inhibition of regulatory pathways by blocking antithrombin synthesis with fitusiran, inhibition of protein $\mathrm{C}$ with antibodies or constructed ser- pins, or inhibition of protein $\mathrm{S}$ have been shown to enhance hemostatic activity in vitro. Fitusiran has been further developed and studied in patients with congenital hemophilia. All these substances may also have the potential to improve hemostasis in AHA in the future, although no clinical studies in such patients are planned as yet [58].

\subsection{Inhibitor Eradication}

Modern hemostatic therapy is highly effective in stopping and preventing bleeding but has no effect on the underlying autoimmune process. Patients remain at risk of bleeding until the inhibitors have been eradicated. Spontaneous remissions have been reported, and patients with low titer inhibitors and higher factor VIII levels in particular may be candidates for a "watch and wait" strategy when not bleeding, but current treatment guidelines generally recommend immunosuppressive therapy to eradicate the inhibitors [7, 19, 23]. However, immunosuppression may be associated with severe side effects, which limits the benefits for patients. Leukopenia, severe infections and sepsis, thrombocytopenia, steroid-induced diabetes, and psychosis have been reported in up to $37 \%$ of patients, with a mortality rate of up to $16 \%$ [9, 18, 20, 29]. Thus, immunosuppressive regimens should be carefully adjusted according to patient age, general condition, and comorbidities, with the benefits of inhibitor eradication balanced against the risk of side effects. In addition, treatment and, ideally, elimination of an underlying condition is mandatory to stop the production of antibodies.

A variety of drugs and treatment protocols for immunosuppression have been published, but no controlled trial has investigated these strategies. Most commonly, corticosteroids (either daily prednisone with $1-2 \mathrm{mg} / \mathrm{kg}$ or pulsed high-dose dexamethasone) alone or in combination with cyclophosphamide (bolus intravenous infusion or daily oral medication) have been used for many years [59]. Other immunosuppressive regimens include azathioprine, bortezomib, and mycophenolate mofetil, among others $[6,18$, $60,61]$. Recently, rituximab has gained increasing acceptance because of the low rate of adverse events, although it is used off label in this indication [18, 62-64]. Data from the $\mathrm{EACH} 2$ registry showed a $58 \%$ remission rate with steroids alone, $80 \%$ with steroids and cyclophosphamide, and $61 \%$ with rituximab-containing combinations [18]. Median time to complete remission (ceased immunosuppression and normal factor VIII levels) was 32, 40, and 64 days, respectively. Adverse events occurred in 25,41, and $37 \%$, respectively, with a mortality rate from complications due to immunosuppression of 3.8\%. The GTH AH-01/2010 trial studied 102 patients with AHA using an escalating immunosuppressive protocol with an initial 3-weeks phase with steroids alone, addition of cyclophosphamide in non-responding patients, and switch to rituximab after 3 further weeks in patients with 
refractory disease [9]. In this study, $48 \%$ of patients achieved partial remission on steroids alone, $21 \%$ with steroids plus cyclophosphamide, and $12 \%$ switched to rituximab. The overall rate of partial remission was $83 \%$ after a median of 31 days, and the rate of complete remission was $61 \%$ after 79 days. However, the rate of immunosuppression-related adverse events was as high as $30 \%$ with a $16 \%$ mortality. The study identified prognostic factors that predicted rates of partial and complete remission and survival $[8,9,11]$ (Fig. 2). These data can be used to individualize immunosuppressive therapy to avoid overtreatment in low-risk patients and undertreatment in high-risk patients. In the UKHCDO study, 40 patients were treated with corticosteroids alone and retrospectively compared with 48 matched patients with additional cyclophosphamide [14]. The median time to remission was not statistically different (49 vs. 39 days). However, a meta-analysis comprising 20 studies with 249 patients demonstrated that cyclophosphamide with or without corticosteroids was more effective in achieving complete remission than corticosteroids alone or no immunosuppressive therapy [16].

Several groups have proposed an alternative approach to eradicating the inhibitors with very high doses of human factor VIII concentrates combined with immunoadsorption, steroids, and intravenous immunoglobulin infusions (BonnMalmö and Budapest protocols for immunotolerance induction) $[38,65]$. The authors reported high success rates at the cost of in part enormous consumption of factor VIII concentrate (and other resource).

All the published data clearly demonstrate that difficulties for patients with AHA no longer related to bleeding

Multivariate Cox Regression

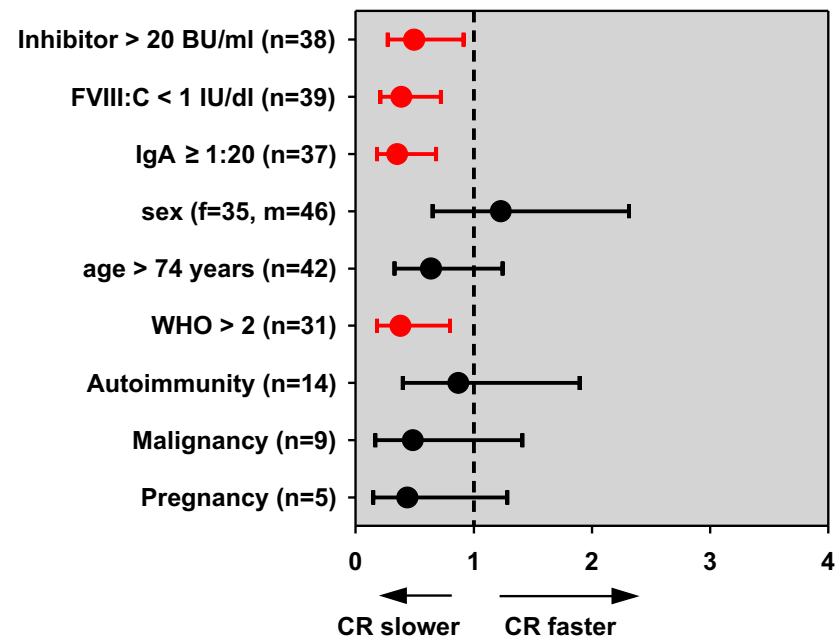

HR with $95 \% \mathrm{Cl}$ intervall and hemostatic therapy but instead to immunosuppression. To prefer rituximab over cytotoxic drugs or steroids is one possibility to avoid the toxic effects of immunosuppression, but this has not yet been studied in controlled trials. Future developments will probably offer other possibilities: discussion about introducing emicizumab as a baseline hemostatic agent to reduce spontaneous new bleeding with a weekly or bi-weekly subcutaneous injection, and use rhFVIIa for short-term treatment of acute bleeding episodes is ongoing. If patients can be stabilized with this strategy, it buys time for a mild immunosuppression (or even none) to reduce inhibitor production or to wait for spontaneous remission. Again, this approach needs to be studied in a controlled clinical trial.

\subsection{Monitoring of Patients with AHA During Therapy}

Patients with AHA must be carefully monitored, as adverse events are common and may even be fatal (Table 5). During episodes of acute bleeding, assessment of bleeding locations and severity should be performed in short intervals (6-12 h). In addition, it is mandatory to look for efficacy, response, and side effects of the applied hemostatic and immunosuppressive therapy. Laboratory tests should cover not only blood counts and clotting factor levels but also parameters detecting neutropenia, infections, diabetes, disseminated coagulopathy, thromboembolism, muscle damage, and organ function. Imaging studies are often necessary to follow hematoma size.

Multivariate Cox Regression

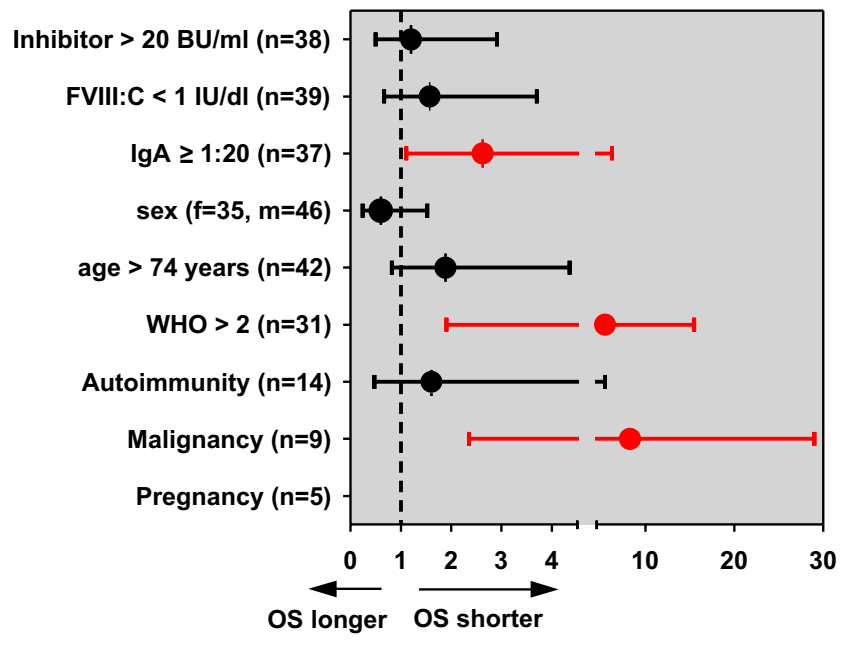

HR with $95 \% \mathrm{Cl}$ intervall

Fig. 2 Prognostic factors of patients with acquired hemophilia A. Data from the GTH AH 01/2010 Study [8, 9]. $C I$ confidence interval, $C R$ complete remission, $H R$ hazard ratio, IgA immunoglobulin A, $O S$ overall survival, WHO World Health Organization performance status 
Table 5 Adverse events, outcomes, and follow-up of patients with acquired hemophilia A

\begin{tabular}{llllllll}
\hline & $\begin{array}{l}\text { Green and } \\
\text { Lechner [15] }\end{array}$ & $\begin{array}{l}\text { Delgado } \\
\text { et al. [16] }\end{array}$ & Collins et al. [14] & $\begin{array}{l}\text { Knoebl et al. } \\
\text { (EACH2) [5] }\end{array}$ & $\begin{array}{l}\text { Borg } \\
\text { et al. [29] } \\
\text { (SACHA) }\end{array}$ & $\begin{array}{l}\text { Tiede et al. } \\
\text { [9] (GTH) }\end{array}$ & $\begin{array}{l}\text { Kessler et al. } \\
\text { (HTRS) [20] }\end{array}$ \\
\hline Deaths reported & $\mathrm{NR}$ & 20 & 42 & 26 & 33 & 33 & NR \\
Estimated 1-year survival & $\mathrm{NR}$ & $\mathrm{NR}$ & $55-72$ & 72 & 62 & 68 & NR \\
Fatal bleeding (\%) & 22 & 11 & 9.1 & 4.5 & 3.5 & 2.9 & NR \\
Fatal CV complications & $\mathrm{NR}$ & $\mathrm{NR}$ & $\mathrm{NR}$ & $\mathrm{NR}$ & 7.3 & 6 & NR \\
Fatal IST-related complications & $\mathrm{NR}$ & $\mathrm{NR}$ & 11 & 4.2 & 12.2 & 16 & NR \\
\hline
\end{tabular}

Data extracted from publications and presented as \%

$C V$ cardiovascular, IST immunosuppressive therapy, $N R$ not reported

During follow-up, patients should be monitored for factor VIII activity and inhibitor levels, new onset of bleeding, and side effects of immunosuppressive therapy.

\subsection{Individualized Therapy and Supportive Care}

AHA is a rare, quite heterogeneous disease in a heterogeneous population of patients. Therefore, clinical studies comparing various therapeutic strategies in a sufficient number of patients cannot be expected. Even the various recommendations that have been published recently can only give some guidance, but important individual circumstances are often not covered. Thus, treatment strategies (the choice of firstline hemostatic agent, response criteria, immunosuppressive regimen, patient's setting, monitoring, comedications, etc.) need to be individualized. Special attention is necessary for patients with active cancer, infection, poor general condition, diabetes, older age, major surgery, large hematomas, compression of vascular structures or other organs. Other concomitant factors enhancing the thromboembolic risk are atrial fibrillation, a history of thromboembolism, a high body mass index, intracoronary and other intravascular stents, immobilization, indwelling catheters, or artificial heart valves. Supportive care needs to include prophylaxis of thromboembolism and even therapeutic anticoagulation as soon as factor VIII levels increase, but that transition is challenging.

\section{Conclusion}

AHA is a rare disease complicated by a lack of knowledge, severe bleeding, multimorbid patients, complex and expensive hemostatic therapy, and severe immunosuppressionrelated side effects, making it one of the most challenging hematologic diseases. Increasing the awareness of AHA so it is recognized as the reason for bleeding is important so the disease is diagnosed quickly and correctly. However, disease management is the domain of specialized dedicated hemophilia treatment centers to provide patients with the best available therapy. Future developments, including highly individualized therapy, new non-factor hemostatic agents, and better immunosuppressive regimens will change its management in the near future, but all these ideas should be studied in well-designed clinical trials.

Acknowledgement Open access funding provided by Medical University of Vienna.

\section{Compliance with Ethical Standards}

Funding No sources of funding were used to conduct this study or prepare this manuscript.

Conflict of interest Paul Knoebl has received research and travel grants from Novo-Nordisk, Baxalta/Shire, Octapharma, and CSL-Behring; consulting fees from Novo-Nordisk, Baxalta/Shire, and Octapharma; and travel grants from Novo-Nordisk, Baxalta/Shire, Octapharma, and CSL-Behring.

Open Access This article is distributed under the terms of the Creative Commons Attribution-NonCommercial 4.0 International License (http://creativecommons.org/licenses/by-nc/4.0/), which permits any noncommercial use, distribution, and reproduction in any medium, provided you give appropriate credit to the original author(s) and the source, provide a link to the Creative Commons license, and indicate if changes were made.

\section{References}

1. Franchini M, Lippi G, Favaloro EJ. Acquired inhibitors of coagulation factors: part II. Semin Thromb Hemost. 2012;38:447-53.

2. Franchini M, Mannucci P. Acquired haemophilia A: a 2013 update. Thromb Haemost. 2013;110:1114-20.

3. Baudo F, De Cataldo F. Acquired hemophilia: a critical bleeding syndrome. Haematologica. 2004;89:96-100.

4. Coppola A, Favaloro E, Tufano A, Di Minno M, Cerbone A, Franchini M. Acquired inhibitors of coagulation factors: part Iacquired hemophilia A. Semin Thromb Hemost. 2012;38:433-46.

5. Knoebl P, Marco P, Baudo F, Collins P, Huth-Kühne A, Nemes L, et al. Demographic and clinical data in acquired hemophilia A: results from the European Acquired Haemophilia Registry 
(EACH2): demographics of acquired hemophilia A. J Thromb Haemost. 2012;10:622-31.

6. Collins PW, Percy CL. Advances in the understanding of acquired haemophilia A: implications for clinical practice. Br J Haematol. 2010;148:183-94.

7. Kruse-Jarres R, Kempton CL, Baudo F, Collins PW, Knoebl $\mathrm{P}$, Leissinger CA, et al. Acquired hemophilia A: updated review of evidence and treatment guidance. Am J Hematol. 2017;92:695-705.

8. Tiede A, Hofbauer CJ, Werwitzke S, Knöbl P, Gottstein S, Scharf $\mathrm{RE}$, et al. Anti-factor VIII IgA as a potential marker of poor prognosis in acquired hemophilia A: results from the GTH-AH 01/2010 study. Blood. 2016;127:2289-97.

9. Tiede A, Klamroth R, Scharf RE, Trappe RU, Holstein K, HuthKühne A, et al. Prognostic factors for remission of and survival in acquired hemophilia A (AHA): results from the GTH-AH 01/2010 study. Blood. 2015;125:1091-7.

10. Hofbauer CJ, Whelan SFJ, Hirschler M, Allacher P, Horling FM, Lawo JP, et al. Affinity of FVIII-specific antibodies reveals major differences between neutralizing and nonneutralizing antibodies in humans. Blood. 2015;125:1180-8.

11. Werwitzke S, Geisen U, Nowak-Göttl U, Eichler H, Stephan B, Scholz U, et al. Diagnostic and prognostic value of factor VIII binding antibodies in acquired hemophilia A: data from the GTHAH 01/2010 study. J Thromb Haemost. 2016;14:940-7.

12. Federici A, Budde U, Castaman G, Rand J, Tiede A. Current diagnostic and therapeutic approaches to patients with acquired von Willebrand syndrome: a 2013 update. Semin Thromb Hemost. 2013;39:191-201.

13. Tiede A, Werwitzke S, Scharf RE. Laboratory diagnosis of acquired hemophilia A: limitations, consequences, and challenges. Semin Thromb Hemost. 2014;40:803-11.

14. Collins PW, Hirsch S, Baglin TP, Dolan G, Hanley J, Makris M, et al. Acquired hemophilia A in the United Kingdom: a 2-year national surveillance study by the United Kingdom Haemophilia Centre Doctors' Organisation. Blood. 2007;109:1870-7.

15. Green D, Lechner K. A survey of 215 non-hemophilic patients with inhibitors to factor VIII. Thromb Haemost. 1981;45:200-3.

16. Delgado J, Jimenez-Yuste V, Hernandez-Navarro F, Villar A. Acquired haemophilia: review and meta-analysis focused on therapy and prognostic factors. Br J Haematol. 2003;121:21-35.

17. Baudo F, Collins P, Huth-Kühne A, Lévesque H, Marco P, Nemes $\mathrm{L}$, et al. Management of bleeding in acquired hemophilia A: results from the European Acquired Haemophilia (EACH2) registry. Blood. 2012;120:39-46.

18. Tengborn L, Baudo F, Huth-Kühne A, Knoebl P, Lévesque H, Marco P, et al. Pregnancy-associated acquired haemophilia A: results from the European Acquired Haemophilia (EACH2) registry. BJOG Int J Obstet Gynaecol. 2012;119:1529-37.

19. Collins P, Baudo F, Knoebl P, Lévesque H, Nemes L, Pellegrini F, et al. Immunosuppression for acquired hemophilia A: results from the European Acquired Haemophilia Registry (EACH2). Blood. 2012;120:47-55

20. Kessler CM, Ma AD, Al-Mondhiry HAB, Gut RZ, Cooper DL. Assessment of acquired hemophilia patient demographics in the United States: the Hemostasis and Thrombosis Research Society Registry. Blood Coagul Fibrinolysis. 2016;27:761-9.

21. Verbruggen B, Novakova I, Wessels H, Boezeman J, Van den Berg M, Mauser-Bunschoten E. The Nijmegen modification of the Bethesda assay for factor VIII: C inhibitors: Improved specificity and reliability. Thromb Haemost. 1995;73:247-51.

22. Toschi V, Baudo F. Diagnosis, laboratory aspects and management of acquired hemophilia A. Intern Emerg Med. 2010;5:325-33.

23. Collins P, Budde U, Rand JH, Federici AB, Kessler CM. Epidemiology and general guidelines of the management of acquired haemophilia and von Willebrand syndrome. Haemophilia. 2008;14:49-55.

24. Kessler CM, Knöbl P. Acquired haemophilia: an overview for clinical practice. Eur J Haematol. 2015;95:36-44.

25. Sallah S. Treatment of acquired haemophilia with factor eight inhibitor bypassing activity. Haemophilia. 2004;10:169-73.

26. Tiede A, Amano K, Ma A, Arkhammar P, Benchikh el Fegoun S, Rosholm A, et al. The use of recombinant activated factor VII in patients with acquired haemophilia. Blood Rev. 2015;29:S19-25.

27. Hedner U, Lee CA. First 20 years with recombinant FVIIa (NovoSeven). Haemophilia. 2011;17:e172-82.

28. Von Depka M. NovoSeven: mode of action and use in acquired haemophilia. Intensive Care Med. 2002;28:s222-7.

29. Borg JY, Guillet B, Le Cam-Duchez V, Goudemand J, Lévesque H. Outcome of acquired haemophilia in France: the prospective SACHA (Surveillance des Auto antiCorps au cours de l'Hémophilie Acquise) registry. Haemophilia. 2013;19:564-70.

30. Hay CRM, Negrier C, Ludlam CA. The treatment of bleeding in acquired haemophilia with recombinant factor VIIa: a multicentre study. Thromb Haemost. 1997;78:1463-7.

31. Abshire T, Kenet G. Recombinant factor VIIa: review of efficacy, dosing regimens and safety in patients with congenital and acquired factor VIII or IX inhibitors. J Thromb Haemost. 2004;2:899-909.

32. Tiede A, Worster A. Lessons from a systematic literature review of the effectiveness of recombinant factor VIIa in acquired haemophilia. Ann Hematol. 2018;97:1889-901.

33. Ehrlich HJ, Henzl MJ, Gomperts ED. Safety of factor VIII inhibitor bypass activity (FEIBA®): 10-year compilation of thrombotic adverse events. Haemophilia. 2002;8:83-90.

34. DiMichele D, Négrier C. A retrospective postlicensure survey of FEIBA efficacy and safety. Haemophilia. 2006;12:352-62.

35. Zanon E, Pasca S, Santoro C, Gamba G, Siragusa SM, Rocino A, et al. Activated prothrombin complex concentrate $($ FEIBA $®)$ in acquired haemophilia A: a large multicentre Italian study-the FAIR Registry. Br J Haematol. 2018. https://doi.org/10.1111/ bjh. 15175 .

36. Turecek PL, Varadi K, Gritsch H, Schwarz HP. FEIBAR: mode of action. Haemophilia. 2004;10:3-9.

37. Váradi K, Negrier C, Berntorp E, Astermark J, Bordet JC, Morfini $\mathrm{M}$, et al. Monitoring the bioavailability of FEIBA with a thrombin generation assay. J Thromb Haemost. 2003;1:2374-80.

38. Nemes L, Pitlik E. New protocol for immune tolerance induction in acquired hemophilia. Haematologica. 2000;85:64-8.

39. Zeitler H, Ulrich-Merzenich G, Panek D, Goldmann G, Vidovic $\mathrm{N}$, Brackmann $\mathrm{HH}$, et al. Immunoadsorption in the treatment of acquired haemophilia. Atheroscler Suppl. 2009;10:122-5.

40. Knobl P, Derfler K, Korninger L, Kapiotis S, Jager U, MaierDobersberger T, et al. Elimination of acquired factor VIII antibodies by extracorporal antibody-based immunoadsorption (IgTherasorb®). Thromb Haemost. 1995;74:1035-8.

41. Zeitler H, Ulrich-Merzenich $\mathrm{G}$, Walger P, Vetter H, Oldenburg J, Goldmann G, et al. Treatment of factor VIII inhibitors with selective IgG immunoadsorption-a single center experience in 50 patients with acquired hemophilia. Transfus Med Hemother. 2006;33:160-4.

42. Jansen M, Schmaldienst S, Banyai S, Quehenberger P, Pabinger I, Derfler K, et al. Treatment of coagulation inhibitors with extracorporeal immunoadsorption (Ig-Therasorb). Br J Haematol. 2001;112:91-7.

43. Knöbl P, Derfler K. Extracorporeal immunoadsorption for the treatment of haemophilic patients with inhibitors to factor VIII or IX. Vox Sang. 1999;77:57-64.

44. Lillicrap D, Schiviz A, Apostol C, Wojciechowski P, Horling F, Lai CK, et al. Porcine recombinant factor VIII (Obizur; OBI-1; 
BAX801): product characteristics and preclinical profile. Haemophilia. 2016;22:308-17.

45. Ewenstein BM, Avorn J, Putnam KG, Bohn RL. Porcine factor VIII: pharmacoeconomics of inhibitor therapy. Haemophilia. 2002;8:13-6.

46. Kempton CL, Abshire TC, Deveras RA, Hoots WK, Gill JC, Kessler CM, et al. Pharmacokinetics and safety of OBI-1, a recombinant $\mathrm{B}$ domain-deleted porcine factor VIII, in subjects with haemophilia A. Haemophilia. 2012;18:798-804.

47. Kruse-Jarres R, St-Louis J, Greist A, Shapiro A, Smith H, Chowdary P, et al. Efficacy and safety of OBI-1, an antihaemophilic factor VIII (recombinant), porcine sequence, in subjects with acquired haemophilia A. Haemophilia. 2015;21:162-70.

48. Stemberger M, Möhnle P, Tschöp J, Ney L, Spannagl M, Reincke M. Successful bleeding control with recombinant porcine factor VIII in reduced loading doses in two patients with acquired haemophilia A and failure of bypassing agent therapy. Haemophilia. 2016;22:e472-4.

49. Tarantino MD, Cuker A, Hardesty B, Roberts JC, Sholzberg M. Recombinant porcine sequence factor VIII (rpFVIII) for acquired haemophilia A: practical clinical experience of its use in seven patients. Haemophilia. 2017;23:25-32.

50. Lenting PJ, Denis CV, Christophe OD. Emicizumab, a bispecific antibody recognizing coagulation factors IX and $\mathrm{X}$ : how does it actually compare to factor VIII? Blood. 2017;130:2463-8.

51. Mancuso ME, Callaghan MU, Kruse-Jarres R, Kempton CL, Xu $\mathrm{J}$, Catalani O, et al. Emicizumab prophylaxis in adolescent/adult patients with hemophilia A previously receiving episodic or prophylactic bypassing agent treatment: updated analyses from the HAVEN 1 Study. Blood. 2017;130:1071.

52. Shima M, Hanabusa H, Taki M, Matsushita T, Sato T, Fukutake $\mathrm{K}$, et al. Long-term safety and efficacy of emicizumab in a phase $1 / 2$ study in patients with hemophilia A with or without inhibitors. Blood Adv. 2017;1:1891-9.

53. Oldenburg J, Mahlangu JN, Kim B, Schmitt C, Callaghan MU, Young G, et al. Emicizumab prophylaxis in hemophilia A with inhibitors. N Engl J Med. 2017;377:809-18.

54. Jimenez-Yuste V, Shima M, Fukutake K, Lehle M, Chebon S, Retout $\mathrm{S}$, et al. Emicizumab subcutaneous dosing every 4 weeks for the management of hemophilia A: preliminary data from the pharmacokinetic run-in cohort of a multicenter, open-label, phase 3 study (HAVEN 4). Blood. 2017;130:86.

55. Knoebl P, Sperr WR, Schellongowski P, Staudinger T, JilmaStohlawetz P, Quehenberger P, Koder S, Ay C, Gleixner KV. Emicizumab for the Treatment of Acquired Hemophilia_A: Lessons Learned from 4 Very Different Cases. Blood 2018;132:2476.

56. Al-Samkari H, Croteau SE. Shifting landscape of hemophilia therapy: implications for current clinical laboratory coagulation assays. Am J Hematol. 2018;93:1082-90.

57. Chowdary P, Lethagen S, Friedrich U, Brand B, Hay C, Abdul Karim F, et al. Safety and pharmacokinetics of anti-TFPI antibody (concizumab) in healthy volunteers and patients with hemophilia: a randomized first human dose trial. J Thromb Haemost. 2015; 13:743-54.

58. Hartmann J, Croteau SE. 2017 Clinical trials update: innovations in hemophilia therapy. Am J Hematol. 2016;91:1252-60.

59. Green D, Rademaker AW, Briet E. A prospective, randomized trial of prednisone and cyclophosphamide in the treatment of patients with factor VIII autoantibodies. Thromb Haemost. 1993;70:753-7.

60. Tiede A, Huth-Kühne A, Oldenburg J, Großmann R, Geisen $\mathrm{U}$, Krause M, et al. Immunosuppressive treatment for acquired haemophilia: current practice and future directions in Germany, Austria and Switzerland. Ann Hematol. 2009;88:365-70.

61. Baudo F, Caimi T, de Cataldo F. Diagnosis and treatment of acquired haemophilia. Haemophilia. 2010;16:102-6.

62. Franchini M, Mannucci PM. Inhibitor eradication with rituximab in haemophilia: where do we stand? $\mathrm{Br} \mathrm{J}$ Haematol. 2014;165:600-8.

63. Zeng Y, Zhou R, Duan X, Long D. Rituximab for eradicating inhibitors in people with acquired haemophilia A. Cochrane Database Syst Rev. 2015;2015:CD011907.

64. Tiede A, Scharf RE, Dobbelstein C, Werwitzke S. Management of acquired haemophilia A. Hamostaseologie. 2015;35:311-8.

65. Zeitler H, Ulrich-Merzenich G, Panek D, Goldmann G, Vidovic $\mathrm{N}$, Brackmann $\mathrm{HH}$, et al. Extracorporeal treatment for the acute und long-term outcome of patients with life-threatening acquired hemophilia. Transfus Med Hemother. 2012;39:264-70. 